https://helda.helsinki.fi

\title{
Prenatal programming of child neurocognitive abilities and maternal mental health : Fetal Programming
}

\section{Tuovinen, Soile}

2020

Tuovinen, S , Lahti-Pulkkinen, M , Rantalainen , V , Kajantie , E \& Räikkönen , K 2020 , '

Prenatal programming of child neurocognitive abilities and maternal mental health : Fetal

Programming ' , Current opinion in endocrine and metabolic research , vol. 13 , pp. 28-38 . https://doi.org/10.1016/j.c

http://hdl.handle.net/10138/326961

https://doi.org/10.1016/j.coemr.2020.09.001

cc_by_nc_nd

publishedVersion

Downloaded from Helda, University of Helsinki institutional repository.

This is an electronic reprint of the original article.

This reprint may differ from the original in pagination and typographic detail.

Please cite the original version. 


\section{Prenatal programming of child neurocognitive abilities and maternal mental health Soile Tuovinen, Marius Lahti-Pulkkinen, Ville Rantalainen, Eero Kajantie and Katri Räikkönen}

\begin{abstract}
Maternal mental health problems during pregnancy, especially mood and anxiety disorders and symptoms, are common. They not only hinder maternal well-being and health during pregnancy but also are associated with physical and mental health adversities in the offspring. We provide here a review of the studies published between 2017 and 2019, which reported on the associations between maternal mental health problems during pregnancy and child neurocognitive outcomes. We identified eight studies, which reported a mixed pattern of findings. While the balance of evidence favors lack of associations, small sample sizes and heterogeneity in study designs, exposures, outcomes, and covariate adjustments between the studies preclude firm conclusions. The reviewed studies encourage further research filling in the knowledge gaps we identified.
\end{abstract}

Corresponding author: Tuovinen, Soile (soile.tuovinen@ helsinki.fi)

Current Opinion in Endocrine and Metabolic Research 2020, 13:28-38

This review comes from a themed issue on Fetal Programming

Edited by Rebecca Reynolds and Susan Ozanne

For a complete overview see the Issue and the Editorial

Available online 16 September 2020

https://doi.org/10.1016/j.coemr.2020.09.001

2451-9650/๑ 2020 Elsevier Ltd. All rights reserved.

\section{Keywords}

Maternal stress, Anxiety, Depression, Cognition, Neurodevelopment, Fetal programming.

\section{Introduction}

Maternal mental health problems during pregnancy are common. Of the maternal mental health problems, depression, including major depressive disorder (MDD) and dysthymia, and anxiety, including panic disorder, generalized anxiety disorder, obsessive-compulsive disorder, post-traumatic stress disorder, and fear of childbirth, are the most common (Antenatal and postnatal mental health: Clinical management and service guidance. Clinical guideline; URL: www.nice.org.uk/ guidance/(cg192). They affect around $10-13 \%$ of the pregnant women [1,2]. The burden increases into 20$30 \%$, if women with clinically relevant, subthreshold symptoms of depression and anxiety are included [3-5]. This burden may be even higher as maternal mental health problems during pregnancy remain often undetected and they are under-represented in surveys. Typical symptoms of depression include loss of interest, depressed mood, hopelessness, worthlessness, sleep and cognitive problems, altered eating patterns, social withdrawal, and suicidal ideation, whereas those of anxiety include panic attacks, hyperventilation, excessive worry, and sleep problems. During pregnancy, typical symptoms may also include doubts of being able to bond with and nurture the infant, thoughts of harming, or thoughts or images of something frightening happening to the baby.

Maternal mental health problems cause a major burden on health and quality of life of the women. They are a key risk factor for suicide, which is among the most common causes of death among women during pregnancy [6,7]. They are also often comorbid with obesity [8] and obstetric complications [9,10] and show high continuity to the postpartum period $[3,4,8,11,12]$. In addition, maternal mental health problems during pregnancy may generate a vicious cycle: one study showed that daughters of women with depression during pregnancy were themselves at 3-fold risk of depression during their own pregnancies [13].

Research conducted over the past two decades has demonstrated that maternal mental health problems may also predict adverse developmental outcomes for the offspring. Infants of women with mental health problems are more often born preterm [14-17] or with lower birth weight $[14,15]$. They also display problems in cognitive, emotional, behavioral, and social development [3,4,18-24]. These findings are in line with the prenatal programming or Developmental Origins of Health and Disease framework; because of high plasticity of the rapidly developing fetal brain, exposure to prenatal environmental adversities may carry adaptive advantages or lasting vulnerabilities on fetal brain development and brain developmental sequelae [18,25-27].

As the literature on this topic has been expanding during the past few years, we provide here a review of articles published between 2017 and 2019. Van den Bergh et al. 
[18] have provided an extensive review of studies published between 2010 and early 2017 on maternal stress during pregnancy and child cognitive and mental health outcomes. The review by Robinson et al. [19] published in 2019 provides a systematic review of studies published between 2014 and 2018 on maternal depression during pregnancy and child neuropsychiatric outcomes. Because the focus of the most recent systematic review was on child neuropsychiatric outcomes, we provide here an update of the studies that have assessed associations between maternal mental health during pregnancy and child neurocognitive abilities, published since the Van den Bergh review. In line with this previous review, we restricted the reviewed studies to those conducted in humans and that were prospective and quasi-experimental, epidemiological, or clinical in study design. We conducted the literature search through PubMed, PsychInfo, and Web of Science using search words related to maternal prenatal stress (stress, distress, anxiety, depression, anxiety disorder, mood disorder, depressive disorder) and words related to child neurodevelopment and cognition (neurodevelopment, cognition, cognitive, cognitive tests, intelligence). We also highlight the articles that we have considered to be of special interest $(*)$ or of outstanding interest $(* *)$.

\section{Child neurocognitive outcomes}

Table 1 provides details of the included studies. Of the eight studies published between 2017 and 2019 and reviewed here, two reported no significant associations between maternal mental health during pregnancy and child neurocognitive abilities in unadjusted models and in models adjusted for covariates; one study reported no significant associations but reported findings from adjusted models only; three studies reported significant unadjusted/partially adjusted associations, which were no longer significant when adjusted for covariates; one study reported significant unadjusted associations, which remained significant after adjustments for all covariates in some subgroups; and one study reported significant unadjusted associations, which remained significant after covariate adjustments.

The studies that found no significant associations in unadjusted or adjusted models are the Greek Rhea Study on prenatal depressive symptoms and child neurodevelopment [28], among 288 mother-child dyads, and a small Swedish study [29] of 39 children who were exposed to maternal mood disorders during pregnancy treated with lithium, to maternal mood disorders during pregnancy not treated with lithium, and who were not exposed to either one. The study that did not find associations and reported adjusted associations only is the multiethnic Dutch Generation R study among 5001 and 1994 mother-child dyads [30].
The three studies that reported significant unadjusted associations, which were no longer significant when adjusted for covariates, are the French Eden study, among 1039 mother-child dyads [12], the Canadian Project Viva, among 1225 mother-child dyads [31], and a small-scale Irish study of 100 children exposed to maternal MDD diagnosed during pregnancy, to history of maternal MDD before pregnancy, or to neither one [32]. The Eden study reported that high maternal depressive symptoms at 24-28 gestational weeks were associated with child's lower verbal, performance, and full-scale intelligence quotient (IQ) at age 5-6 years [12], and the Viva study reported that maternal depressive symptoms in midpregnancy were associated with poorer verbal skills of children at age $7-8$ years [31]. In the Irish study, in partially adjusted models, children of women with MDD diagnosed during pregnancy had lower language development scores at 12 months than children of women with neither MDD nor MDD history [32]. However, these associations were not significant in adjusted models.

The one study that reported significant unadjusted associations, which remained significant after adjustment for all covariates in some subgroups, is the multiethnic Dutch Generation R study [30] among 4251 motherchild dyads. In the Generation $\mathrm{R}$ study, in unadjusted models, higher maternal prenatal stress at 20-25 gestational weeks was associated with lower nonverbal IQ in 6-year-old children in Dutch, Caribbean, and Moroccan/Turkish groups, but after covariate adjustments, this association remained significant in the Moroccan/Turkish group only [33].

The one study that reported significant unadjusted associations, which remained significant after all covariate adjustments, is the Finnish PREDO study [3] among 2231 mother-child dyads. The PREDO study reported that higher maternal depressive symptoms measured biweekly between 12 and 39 gestational weeks were associated with lower total developmental milestone scores and with higher odds to display at least mild developmental delay across communication, gross motor, fine motor, problem solving, and personal/social skills in children at age 2-6 years. The children of mothers with consistently high/clinically relevant depressive symptoms during pregnancy had the lowest total developmental milestone score of these skills.

\section{Discussion}

This review focused on the recent studies on the associations between maternal mental health problems during pregnancy and child neurocognitive outcomes. The reviewed findings were inconsistent and varied according to the studied maternal stressor, child neurocognitive outcome, study design, and population. Seven studies focused on maternal prenatal depression. 


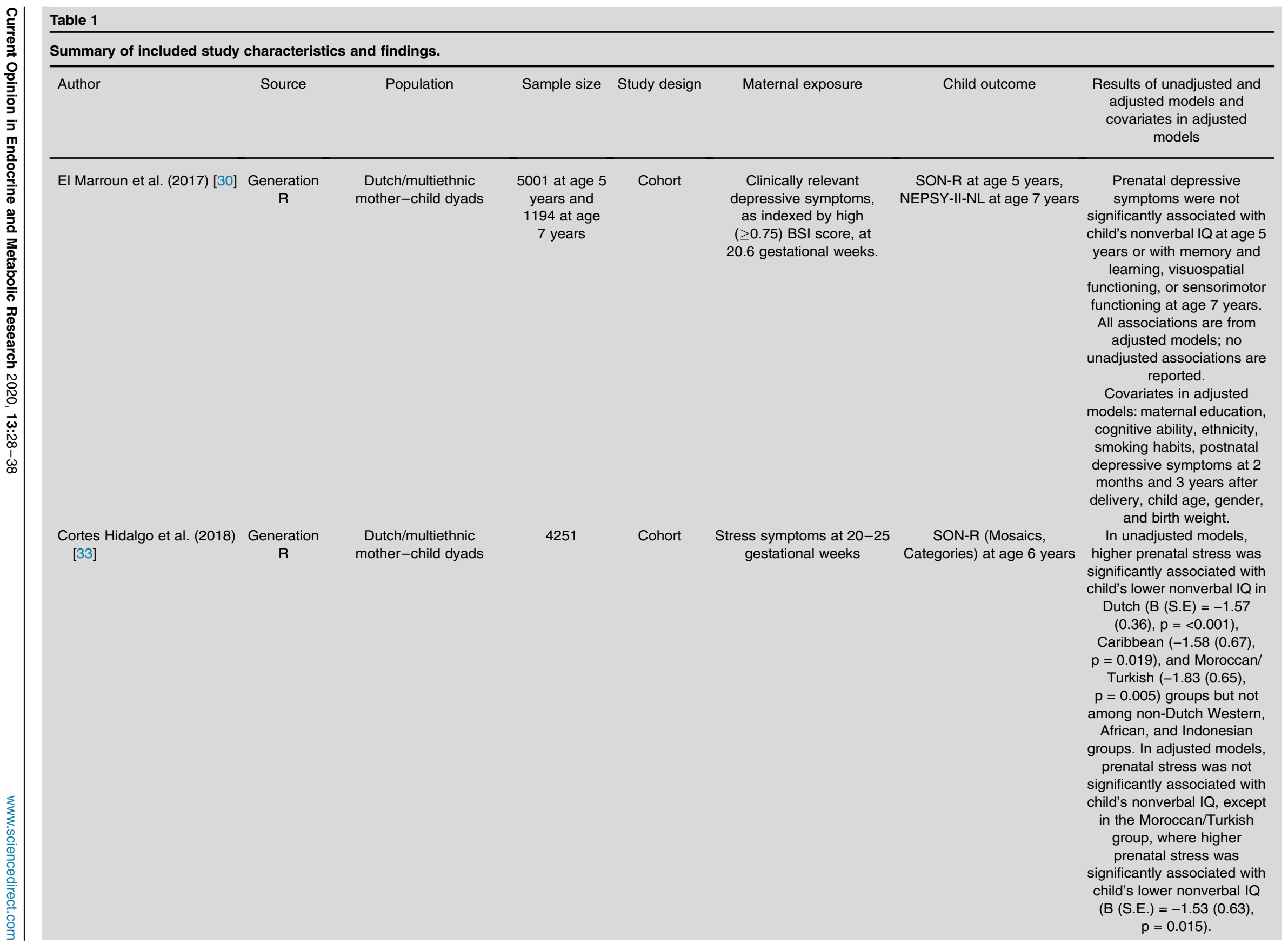




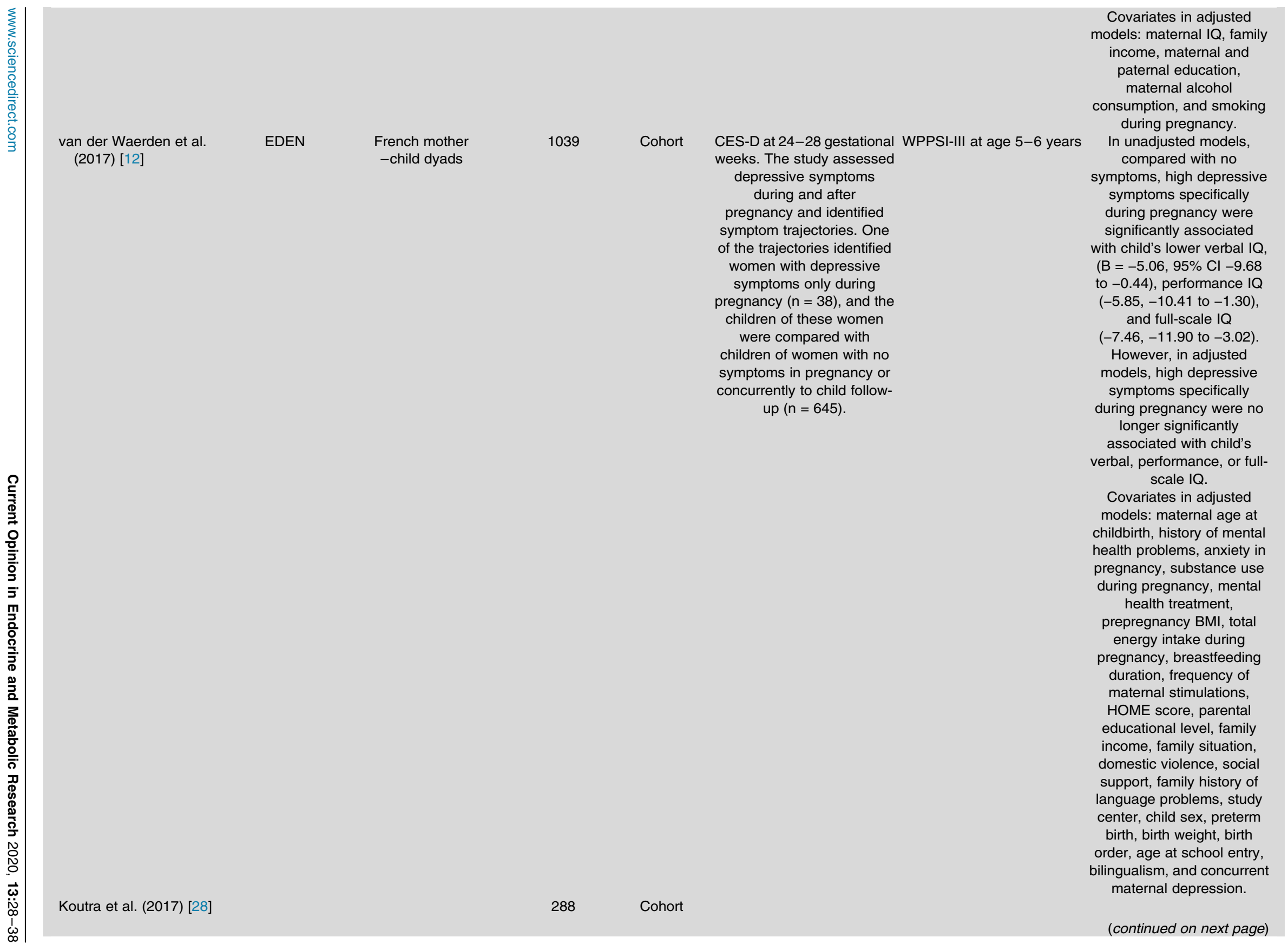




\begin{tabular}{|c|c|c|c|c|c|c|c|}
\hline Author & Source & Population & Sample size & Study design & Maternal exposure & Child outcome & $\begin{array}{c}\text { Results of unadjusted and } \\
\text { adjusted models and } \\
\text { covariates in adjusted } \\
\text { models }\end{array}$ \\
\hline Tuovinen et al. (2018) [3] & $\begin{array}{l}\text { Rhea } \\
\text { Study }\end{array}$ & Finnish mother-child dyads & 2231 & Cohort & $\begin{array}{l}\text { CES-D biweekly between } \\
\text { weeks }+ \text { days } 12+0 / 13+6 \\
\text { and } 38+0 / 39+6 \text { or } \\
\text { delivery. Continuous and } \\
\text { categorical depression } \\
\text { scores and trajectories of } \\
\text { depressive symptoms were } \\
\text { used as independent } \\
\text { variables. }\end{array}$ & $\begin{array}{l}\text { MSCA (Verbal, Quantitative, } \\
\text { Memory, Perceptual- } \\
\text { Performance, and Motor } \\
\text { scales) at } \\
\text { age } 4 \text { years }\end{array}$ & $\begin{array}{c}\text { Prenatal depressive } \\
\text { symptoms were not } \\
\text { significantly associated with } \\
\text { child's verbal or quantitative } \\
\text { memory, perceptual } \\
\text { performance, or motor } \\
\text { abilities in unadjusted or } \\
\text { adjusted models. } \\
\text { Covariates in adjusted } \\
\text { models: quality of } \\
\text { assessment, child sex, } \\
\text { examiner, maternal age at } \\
\text { delivery, maternal } \\
\text { education, working status at } \\
4 \text { years, maternal smoking } \\
\text { at } 4 \text { years, number of } \\
\text { children in the family, } \\
\text { breastfeeding duration, } \\
\text { child's day care at } \\
\text { assessment, TV watching. } \\
\text { Higher prenatal depressive } \\
\text { symptoms were significantly } \\
\text { associated with child's lower } \\
\text { total developmental } \\
\text { milestone scores } \\
\text { (B = - } 0.84 .95 \% \text { Cl, }-1.13 \\
\text { to -0.55, } \mathrm{p}<0.001 \text { ) and with } \\
\text { child's higher odds to } \\
\text { display at least mild } \\
\text { developmental delay } \\
\text { (OR = } 1.33,95 \% \mathrm{Cl}, 1.17 \text { to } \\
1.50, \mathrm{p}<0.001) \text { in } \\
\text { unadjusted and adjusted } \\
\text { models. } \\
\text { Covariates in adjusted } \\
\text { models: maternal age, } \\
\text { parity, education, } \\
\text { occupation, history of } \\
\text { depression, antidepressant } \\
\text { and other psychotropic } \\
\text { medication use, alcohol use } \\
\text { and smoking during } \\
\text { pregnancy, type } 1 \text { diabetes, } \\
\text { chronic hypertension, early } \\
\text { pregnancy body mass }\end{array}$ \\
\hline
\end{tabular}


Swedish mother-child dyads
39

Clinical cohort

mood disorder and

lithium treatment during pregnancy, 8 mood disorder and no lithium treatment during pregnancy, 11 no mood disorder and no lithium treatment during

$$
\text { pregnancy }
$$

index, gestational diabetes, hypertensive pregnancy disorders, family structure child age and sex

gestational length, and child's birth weight for gestation. The effects of maternal prenatal

depressive symptoms were also independent of depressive symptoms postpartum and in early childhood.

WPPSI-III at age 4-5 years No significant differences were found between the groups in child's verbal groups in child's verbal, performance, or full-scale IQ
in unadjusted or adjusted models.

However, in unadjusted models, children of women with mood disorders with $(B=-7,8, p=0.05)$ or without $(B=-10.3, p=0.04)$ lithium treatment scored lower on processing speed quotient than children of women without mood disorder and lithium treatment. In models adjusted for prematurity, the significant difference

between children of women with mood disorders and without lithium treatment without lithium treatment
and those not exposed was not significant, and in models adjusting for maternal education and social problems, the significant difference between children of women with mood disorders and with lithium treatment and those not exposed was not significant. None of the models adjusted for all covariates

Covariates in adjusted models: child prematurity or (continued on next page) 
Table 1. (continued)

\begin{tabular}{lcccc}
\hline Author & Source & Population & Sample size Study design & Maternal exposure \\
\hline O'Leary et al. (2019) [32] & Irish mother-child dyads & 100 & Case control outcome & $\begin{array}{c}23 \text { MDD diagnosed during } \\
\text { pregnancy, } 34 \text { MDD history } \\
\text { and euthymic during } \\
\text { pregnancy, } 43 \text { no MDD } \\
\text { diagnosis during pregnancy } \\
\text { or history of MDD }\end{array}$
\end{tabular}

Faleschini et al. (2019) [31] Project Viva Canadian mother-child

$$
\text { dyads }
$$

$$
\text { or history of MDD }
$$

maternal level of education

and social problems.

Children of women with

MDD diagnosed during

pregnancy had significantly lower language

development scores at 12 months $(\mathrm{M}=87.33$ $\mathrm{SD}=10.54$ vs $\mathrm{M}=95.06$, $\mathrm{SD}=11.78, \mathrm{p}=0.037$ ) than children of women with no MDD or MDD history. All associations are from adjusted models; no

unadjusted associations are reported.

Covariates in models: maternal education and parity.

In models also adjusting for concurrent maternal depressive

symptom scores, the association with language development became nonsignificant, and motor development score at 6 months became significant ( $M=95.48, S D=11.87$ for children of women with MDD vs $99.97, S D=10.6$ for children of women with no MDD or MDD history, $p=0.026$ ). No significant associations with child's general cognitive

development scores at 6 or 12 months or with language development at 6 months or motor development at 12 months were found.

High EPDS score $(\geq 13)$ in KBIT-2, WRAVMA, WRAML midpregnancy $<22$ at age $7-8$ years In unadjusted prenatal depressive gestational weeks $(n=122)$ 


$$
\text { maternal IQ. }
$$

ASQ, Ages and Stages Questionnaire; B, unstandardized regression coefficient; BMI, body mass index; BSID-III, Bayley Scale of Infant Development - 3rd edition; BRIEF-P, Behavior Rating Inventory of Executive Function - Preschool Version; BSI, Brief Symptom Inventory; CES-D, Center for Epidemiologic Studies Depression Scale; CI, confidence interval; EPDS, Edinburgh Postnatal Depression Scale; EPQ-R, Eysenck Personality Questionnaire - Revised; HOME score, Home Observation for the Measurement of the Environment Scale; IQ, intelligence quotient; KBIT-2, Kaufman Brief Intelligence Test; M, mean; MDD, major depressive disorder; MSCA, McCarthy Scales of Children's Abilities; NEPSY-II-NL, Dutch version of the NEPSY-II; OR, odds ratio; S.E., standard error; SD, standard deviation; SON-R, Snijders-Oomen Niet-verbale intelligentie Test-Revisie (nonverbal IQ); WPPSI-III, Wechsler Preschool and Primary Scale of Intelligence - 3rd edition; WRAML, Visual Memory Index of the Wide Range Assessment of Memory and Learning; WRAVMA, Wide Range Assessment of Visual Motor Abilities. 
Significant associations of maternal prenatal depression in children with lower IQ and poorer general neurodevelopment, developmental delay, and motor and language development were found. However, findings were mixed, and only rarely did associations of maternal depression and child neurodevelopment remain significant after adjustment for maternal, neonatal, and/or child characteristics. In addition, only one study examined the associations between maternal prenatal stress symptoms and child neurocognitive outcomes, and the findings varied according to the ethnicity of the participants. Interestingly, none of the studies focused on maternal anxiety disorders or symptoms. Methodological limitations were present in many studies, as described in detail in the following paragraphs.

All eight studies included in this study were conducted in high-income countries, which limits the generalizability of the findings to other populations. The Finnish PREDO study [3] and the Swedish clinical cohort study [29] examined European Nordic populations. The French EDEN [12], and Irish O'Leary [32] studies comprised southern European populations, while the Dutch Generation R studies [30,33] comprised a multiethnic European population. The Greek Rhea study [28] included both Greek and immigrant participants. Only the Canadian Project Viva study [31] was conducted outside Europe.

Seven studies were cohort studies, one of which was a clinical cohort [29]. One study was a case-control study [32]. Two studies used objective maternal stress measures, mood disorder diagnoses, or MDD [29,32]. Five other studies used validated maternal self-report questionnaires, Brief Symptom Inventory [30], Center for Epidemiologic Studies Depression Scale [3,12], and Edinburgh Postnatal Depression Scale [28,31]. One study used a self-report composite stress score including contextual, personal, interpersonal, and life stress which had previously shown good model fit [34]. Only one study measured prenatal symptoms at multiple time points, enabling assessment of gestation-specific effects [3].

The studies also varied in what covariates and confounders were accounted for, further complicating interpretations across the different studies. While 5 studies accounted for child sex, three did not [29,32,33]. All except two studies [29,32] controlled for maternal substance use during pregnancy. Three studies controlled for prepregnancy and pregnancy disorders and/or gestational age and/or birth weight $[3,12,29]$. One study additionally controlled for paternal education [33], two studies for family income [12,33], and three studies for maternal cognitive ability or IQ [30,31,33], each of which account for genetic and postnatal environmental effects. One study controlled for anxiety in pregnancy, which may have induced statistical multicollinearity. Four studies controlled for maternal postnatal or concurrent depressive symptoms $[3,12,30,32]$. Hence, many studies left open the question whether the associations or lack of them were specific to the prenatal period.

Four studies reported selective nonresponse among social disadvantaged families or less educated mothers $[3,12,29,33]$. Hence, the selection bias in participation may have influenced the results and limit generalizability.

Focus on different domains of cognition and variations in methods for measuring cognition may also explain the contradictory results. One study used parental reports [3] and others used objective tests of neurocognitive outcomes. Studies combining different methods would yield the most comprehensive picture of child neurodevelopment.

Finally, many of the studies included in this review were conducted in small samples. Null findings may therefore reflect lack of statistical power rather than a true lack of association. Publication bias is also a possibility and should be taken into account when interpreting the findings.

Our findings of inconsistent associations between maternal mental health during pregnancy and child neurodevelopment are somewhat contradictory to those of the review by Van den Bergh et al. [18], which concluded that maternal psychological distress during pregnancy was associated with poorer neurocognitive and especially motor development in the offspring. However, also that study pointed out that the effect sizes were small and the findings needed replication.

The biological mechanisms underlying the possible effects of maternal prenatal mental health on offspring neurocognitive development may include genetic and epigenetic changes in the structure and functioning of the placenta, in the activity of the glucocorticoid regulation of the hypothalamus-pituitary-adrenal axis regulating the stress response, and in the functioning of the inflammatory system. Studies in PREDO showed that maternal depression and/or anxiety during pregnancy were associated with increased levels of proinflammatory biomarkers high-sensitive G-reactive protein and glycoprotein throughout pregnancy [35], with morphological changes in the placenta [36], with changes in placental mRNA expression of genes regulating glucocorticoid functioning [37], and with lower epigenetic gestational age [38] and altered polyepigenetic scores of glucocorticoid-responsive genes [39] of the newborn. The increased maternal proinflammatory biomarker levels during pregnancy also predicted increased neurodevelopmental delay risk in 
the offspring and mediated the effects of prenatal adversity on child neurodevelopmental delay [40]. Maternal treatment with synthetic glucocorticoids during pregnancy also associated with depressive symptoms during pregnancy and predicted offspring risk of neurodevelopmental delay [41]. Other longitudinal studies also suggest placental epigenetic changes in glucocorticoid-regulating genes as a consequence of maternal prenatal anxiety [42] and poorer neurodevelopment in children overexposed to maternal glucocorticoids due to maternal prenatal licorice consumption [43]. Genetic factors may also contribute, as the genetic polymorphisms predicting depression risk may have pleiotropic effects of neurocognitive development [44].

To conclude, findings on the associations between maternal prenatal mental health problems and child neurocognitive outcomes are inconsistent. While most recent findings do not support an independent effect, representative studies in larger study samples assessing and comparing the effects of different maternal stressors are needed to elucidate whether maternal prenatal mental health is associated with neurocognitive development in their children.

\section{Funding}

This work was supported by the EVO (a special state subsidy for health science research), University of Helsinki Research Funds, the Academy of Finland, European Union's Horizon 2020 Award SC1-2016-RTD733280 for RECAP, European Commission Dynamics of Inequality Across the Life-course: structures and processes (DIAL) No 724363 for PremLife.

\section{Conflict of interest statement}

Nothing declared.

\section{Acknowledgements}

Soile Tuovinen, PhD, Marius Lahti-Pulkkinen, PhD, Ville Rantalainen, PhD, Department of Psychology and Logopedics, Faculty of Medicine, University of Helsinki, Finland; Eero Kajantie, Prof, National Institute for Health and Welfare, Helsinki, Finland; PEDEGO Research Unit, MRC Oulu, Oulu University Hospital and University of Oulu, Oulu, Finland; Children's Hospital, Helsinki University Hospital and University of Helsinki, Helsinki, Finland; Department of Clinical and Molecular Medicine, Norwegian University for Science and Technology, Trondheim, Norway; Katri Räikkönen, Prof, Department of Psychology \& Logopedics, University of Helsinki, PL 21, 00014, Helsinki, Finland, katri.raikkonen@ helsinki.fi.

\section{References}

Papers of particular interest, published within the period of review, have been highlighted as:

* of special interest

1. Goodman JH, Chenausky KL, Freeman MP: Anxiety disorders during pregnancy: a systematic review. J Clin Psychiatr 2014, 75:e1153-e1184.

2. Wallwiener S, Goetz M, Lanfer A, Gillessen A, Suling M, Feisst M, Sohn C, Wallwiener M: Epidemiology of mental disorders during pregnancy and link to birth outcome: a large-scale retrospective observational database study including 38,000 pregnancies. Arch Gynecol Obstet 2019, 299:755-763.

3. Tuovinen S, Lahti-Pulkkinen M, Girchenko P, Lipsanen J, Lahti J, Heinonen K, Reynolds RM, Hämäläinen E, Kajantie E, Laivuori H, et al:: Maternal depressive symptoms during and after pregnancy and child developmental milestones. Depress Anxiety 2018, 35:732-741.

Important study that demonstrated that higher maternal prenatal depressive symptoms were associated with child lower total developmental milestones score and with child higher odds to display at least mild developmental delay. The only study of the reviewed studies that measured maternal depressive symptoms throughout pregnancy.

4. Lahti M, Savolainen K, Tuovinen S, Pesonen A-K, Lahti J, Heinonen K, Hämäläinen E, Laivuori H, Villa PM, Reynolds RM, et al.: Maternal depressive symptoms during and after pregnancy and psychiatric problems in children. J Am Acad Child Adolesc Psychiatry 2017, 56:30-39.

5. Molyneaux E, Poston L, Ashurst-Williams S, Howard LM: Obesity and mental disorders during pregnancy and postpartum: a systematic review and meta-analysis. Obstet Gynecol 2014, 123:857-867.

6. Chang J, Berg CJ, Saltzman LE, Herndon J: Homicide: a leading cause of injury deaths among pregnant and postpartum women in the United States, 1991-1999. Am J Publ Health 2005, 95:471-477.

7. Nock MK, Borges G, Bromet EJ, Cha CB, Kessler RC, Lee S: Suicide and suicidal behavior. Epidemiol Rev 2008, 30: 133-154.

8. Kumpulainen SM, Girchenko P, Lahti-Pulkkinen M, Reynolds RM Tuovinen S, Pesonen A-K, Heinonen K, Kajantie E, Villa PM, Hämäläinen E, et al.: Maternal early pregnancy obesity and depressive symptoms during and after pregnancy. Psychol Med 2018, 48:2353-2363.

9. Kurki T, Hiilesmaa V, Raitasalo R, Mattila H, Ylikorkala O: Depression and anxiety in early pregnancy and risk for preeclampsia. Obstet Gynecol 2000, 95:487-490.

10. Qu C, Williams MA, Calderon-Margalit R, Cripe SM, Sorensen TK: Preeclampsia risk in relation to maternal mood and anxiety disorders diagnosed before or during early pregnancy. Am J Hypertens 2009, 22:397-402.

11. Evans J, Melotti R, Heron J, Ramchandani P, Wiles N, Murray L, Stein A: The timing of maternal depressive symptoms and child cognitive development: a longitudinal study. J Child Psychol Psychiatry Allied Discip 2012, 53:632-640.

12. van der Waerden J, Bernard JY, De Agostini M, SaurelCubizolles MJ, Peyre H, Heude B, Melchior M, Annesi-Maesano I, Bernard JY, Botton J, et al.: Persistent maternal depressive symptoms trajectories influence children's IQ: the EDEN mother-child cohort. Depress Anxiety 2017, 34:105-117.

13. Pearson RM, Carnegie RE, Cree C, Rollings C, Rena-Jones L, Evans J, Stein A, Tilling K, Lewcock M, Lawlor DA: Prevalence of prenatal depression symptoms among 2 generations of pregnant mothers: the avon longitudinal study of parents and children. JAMA Netw Open 2018, 1:e180725.

14. Bussières EL, Tarabulsy GM, Pearson J, Tessier R, Forest JC, Giguère $Y$ : Maternal prenatal stress and infant birth weight and gestational age: a meta-analysis of prospective studies. Dev Rev 2015, 36:179-199.

15. Grote NK, Bridge JA, Gavin AR, Melville JL, lyengar S, Katon WJ: A meta-analysis of depression during pregnancy and the risk of preterm birth, low birth weight, and intrauterine growth restriction. Arch Gen Psychiatr 2010, 67:1012-1024.

16. Pesonen AK, Lahti M, Kuusinen T, Tuovinen S, Villa P Hämäläinen E, Laivuori H, Kajantie E, Räikkönen K: Maternal prenatal positive affect, depressive and anxiety symptoms and birth outcomes: the PREDO study. PloS One 2016, 11: $1-13$.

17. Grigoriadis S, VonderPorten EH, Mamisashvili L, Tomlinson G, Dennis C-L, Koren G, Steiner M, Mousmanis P, Cheung A, Radford K, et al:: The impact of maternal depression during 
pregnancy on perinatal outcomes: a systematic review and meta-analysis. J Clin Psychiatr 2013, 74:e321-e341.

18. Van den Bergh BRH, van den Heuvel MI, Lahti M, Braeken M, de Rooij SR, Entringer S, Hoyeri D, Roseboom T, Räikkönen K, Suzanne Kingk MS: Prenatal developmental origins of behavior and mental health: the influence of maternal stress in pregnancy. Neurosci Biobehav Rev 2017. S0149-7634: 30734-5.

19. Robinson R, Lahti-Pulkkinen M, Heinonen K, Reynolds RM Räikkönen K: Fetal programming of neuropsychiatric disorders by maternal pregnancy depression: a systematic mini review. Pediatr Res 2019, 85:134-145.

Important systematic review on maternal depression and offpsring neuropsychiatric disorders.

20. Wolford E, Lahti M, Tuovinen S, Lahti J, Lipsanen J, Savolainen K, Heinonen K, Hämäläinen E, Kajantie E, Pesonen A-K, et al:: Maternal depressive symptoms during and after pregnancy are associated with attention-deficit/ hyperactivity disorder symptoms in their 3- to 6-year-old children. PlOS One 2017, 12:e0190248.

21. Madigan S, Oatley H, Racine N, Fearon RMP, Schumacher L, Akbari E, Cooke JE, Tarabulsy GM: A meta-analysis of maternal prenatal depression and anxiety on child socioemotional development. J Am Acad Child Adolesc Psychiatry 2018, 57. 645-657.e8.

22. Manzari N, Matvienko-Sikar K, Baldoni F, O'Keeffe GW Khashan AS: Prenatal maternal stress and risk of neurodevelopmental disorders in the offspring: a systematic review and meta-analysis. Soc Psychiatr Psychiatr Epidemiol 2019, 54:1299-1309.

23. Raikkonen K, Seckl JR, Pesonen A-K, Simons A, Van den Bergh BRH: Stress, glucocorticoids and liquorice in human pregnancy: programmers of the offspring brain. Stress 2011 , 14:590-603.

24. Toffol E, Lahti-Pulkkinen M, Lahti J, Lipsanen J, Heinonen K Pesonen AK, Hämäläinen E, Kajantie E, Laivuori H, Villa PM, et al: Maternal depressive symptoms during and after pregnancy are associated with poorer sleep quantity and quality and sleep disorders in 3.5-year-old offspring. Sleep Med 2019 56:201-210.

25. Barker DJP: The origins of the developmental origins theory J Intern Med 2007:412-417.

26. O'Donnell KJ, Meaney MJ: Fetal origins of mental health: the developmental origins of health and disease hypothesis. Am J Psychiatr 2017, 174:319-328.

27. Lupien SJ, McEwen BS, Gunnar MR, Heim C: Effects of stress throughout the lifespan on the brain, behaviour and cognition. Nat Rev Neurosci 2009, 10:434-445.

28. Koutra K, Roumeliotaki T, Kyriklaki A, Kampouri M, Sarri K, Vassilaki M, Bitsios P, Kogevinas M, Chatzi L: Maternal depression and personality traits in association with child neuropsychological and behavioral development in preschool years: mother- child cohort (Rhea Study) in Crete, Greece. J Affect Disord 2017, 217:89-98.

29. Forsberg L, Adler M, Römer Ek I, Ljungdahl M, Navér L, Gustafsson LL, Berglund G, Chotigasatien A, Hammar U, Böhm B, et al:: Maternal mood disorders and lithium exposure in utero were not associated with poor cognitive development during childhood. Acta Paediatr Int J Paediatr 2018, 107 $1379-1388$.

30. El Marroun H, White TJ, Fernandez G, Jaddoe VW, Verhulst FC Stricker BH, Tiemeier H: Prenatal exposure to selective serotonin reuptake inhibitors and non-verbal cognitive functioning in childhood. J Psychopharmacol 2017, 31:346-355.

31. Faleschini S, Rifas-Shiman SL, Tiemeier H, Oken E, Hivert MF: Associations of prenatal and postnatal maternal depressive symptoms with offspring cognition and behavior in midchildhood: a prospective cohort study. Int J Environ Res Publ Health 2019, 16:1-11.
32. O'Leary N, Jairaj C, Molloy EJ, McAuliffe FM, Nixon E O'Keane V: Antenatal depression and the impact on infant cognitive, language and motor development at six and twelve months postpartum. Early Hum Dev 2019, 134:41-46.

33. Cortes Hidalgo AP, Neumann A, Bakermans-Kranenburg MJ, Jaddoe VWV, Rijlaarsdam J, Verhulst FC, White T, van IJzendoorn MH, Tiemeier H: Prenatal maternal stress and child IQ. Child Dev 2018:1-19.

A multi-ethnic study that demonstrated that maternal prenatal stress was associated with child $I Q$, but only in one ethnic group of the multiethnic sample. The study encourages further research on risk and resiliency following exposure to prenatal environmental adversity.

34. Rijlaarsdam J, Pappa I, Walton E, Bakermans-Kranenburg MJ Mileva-Seitz VR, Rippe RCA, Roza SJ, Jaddoe VWV,

Verhulst FC, Felix JF, et al:: An epigenome-wide association meta-analysis of prenatal maternal stress in neonates: a model approach for replication. Epigenetics 2016, 11:140-149.

35. Lahti-Pulkkinen M, Girchenko P, Robinson R, Lehto SM, Toffol E, Heinonen K, Reynolds RM, Kajantie E, Laivuori H, Villa PM, et al: Maternal depression and inflammation during pregnancy Psychol Med 2019, https://doi.org/10.1017/S0033291719001909.

36. Lahti-Pulkkinen M, Cudmore MJ, Haeussner E, Schmitz C, Pesonen A-K, Hämäläinen E, Villa PM, Mehtälä S, Kajantie E, Laivuori $\mathrm{H}$, et al.: Placental morphology is associated with maternal depressive symptoms during pregnancy and toddler psychiatric problems. Sci Rep 2018, 8:791.

37. Räikkönen K, Pesonen AK, O’Reilly JR, Tuovinen S, Lahti M, Kajantie E, Villa P, Laivuori H, Hämäläinen E, Seckl JR, et al.: Maternal depressive symptoms during pregnancy, placental expression of genes regulating glucocorticoid and serotonin function and infant regulatory behaviours. Psychol Med 2015, 45:3217-3226

38. Suarez A, Lahti J, Czamara D, Lahti-pulkkinen M, Knight AK, Girchenko P, Hämäläinen E, Kajantie E, Lipsanen J, Laivuori H, et al:: The epigenetic clock at birth: associations with maternal antenatal depression and child psychiatric problems. J Am Acad Child Adolesc Psychiatry 2018, 57:321-328.

39. Provençal N, Arloth J, Cattaneo A, Anacker C, Cattane N, Wiechmann T, Röh S, Ködel M, Klengel T, Czamara D, et al:: Glucocorticoid exposure during hippocampal neurogenesis primes future stress response by inducing changes in DNA methylation. Proc Natl Acad Sci U S A 2019, https://doi.org/ 10.1073/pnas.1820842116.

40. Girchenko P, Lahti-Pulkkinen M, Heinonen K, Reynolds RM, Laivuori $\mathrm{H}$, Lipsanen J, Villa PM, Hämäläinen E, Kajantie E, Lahti J, et al:: Persistently high levels of maternal antenatal inflammation are associated with and mediate the effect of prenatal environmental adversities on neurodevelopmental delay in the offspring. Biol Psychiatr 2019, https://doi.org/ 10.1016/j.biopsych.2019.12.004.

41. Wolford E, Lahti-Pulkkinen M, Girchenko P, Lipsanen J, Tuovinen S, Lahti J, Heinonen K, Hämäläinen E, Kajantie E, Pesonen A-K, et al:: Associations of antenatal glucocorticoid exposure with mental health in children. Psychol Med 2019, https://doi.org/10.1017/S0033291718004129.

42. O’Donnell KJ, Bugge Jensen A, Freeman L, Khalife N, O'Connor TG, Glover V: Maternal prenatal anxiety and downregulation of placental $11 \beta$-HSD2. Psychoneuroendocrinology 2012, 37:818-826.

43. Räikkönen K, Martikainen S, Pesonen AK, Lahti J, Heinonen K, Pyhälä R, Lahti M, Tuovinen S, Wehkalampi K, Sammallahti S, et al.: Maternal licorice consumption during pregnancy and pubertal, cognitive, and psychiatric outcomes in children. Am J Epidemiol 2017, 185:317-328.

44. Howard DM, Adams MJ, Clarke TK, Hafferty JD, Gibson J, Shirali M, Coleman JRI, Hagenaars SP, Ward J, Wigmore EM, et al: Genome-wide meta-analysis of depression identifies 102 independent variants and highlights the importance of the prefrontal brain regions. Nat Neurosci 2019, 22:343-352. 